\title{
Effects of Nucleotides and Sugar Nucleotides on Mannosyltransferase Activity in Saccharomyces cerevisiae
}

\author{
By CHARLES R. HARRINGTON AND L. JULIA DOUGLAS* \\ Department of Microbiology, University of Glasgow, Alexander Stone Building, \\ Garscube Estate, Bearsden, Glasgow G61 1QH, U.K.
}

(Received 28 November 1980; revised 19 January 1981)

\begin{abstract}
A survey was made of the effects of different nucleotides, sugar nucleotides and sugars on mannosyltransferase activity in Saccharomyces cerevisiae to assess their possible role in the regulation of mannan synthesis. Mannosyltransferase activity in spheroplast lysate and washed membrane preparations was not markedly affected by sugars, nucleoside monophosphates or by most of the sugar nucleotides tested. GDP and GTP both inhibited enzyme activity. ATP caused a significant stimulation, and analysis of the mannan formed suggested that this was due mainly to increased synthesis of the polysaccharide moiety. GDPglucose was a competitive inhibitor of total mannan synthesis and also inhibited the formation of mannolipids.
\end{abstract}

\section{INTRODUCTION}

The major components of the cell wall of Saccharomyces cerevisiae are mannan (Ballou, 1976 ) and three $\beta$-glucans (Manners et al., 1973a,b; Fleet \& Manners, 1976). Mannan is present as a mixture of mannoproteins in which the carbohydrate moieties comprise short alkali-labile oligosaccharides attached to serine or threonine residues, and long polysaccharide chains linked via di- $N$-acetylchitobiose to asparagine (Ballou, 1976). Biosynthesis of the carbohydrate chains probably involves at least ten different mannosyltransferases, each one catalysing the formation of a specific glycosidic linkage (Nakajima \& Ballou, 1975). The mannosyl residues all originate from GDPmannose (Behrens \& Cabib, 1968) either by direct transfer or via lipid intermediates which have been identified as dolichyl phosphate derivatives (Jung \& Tanner, 1973). $\beta$-Glucans have been synthesized in vitro from UDPglucose (Sentandreu et al., 1975; López-Romero \& Ruiz-Herrera, 1977; Shematek et al., 1980) and from GDPglucose (Bálint et al., 1976).

Relatively little is known about the regulation of glucan and mannan biosynthesis. Shematek \& Cabib (1980) have shown that 1,3- $\beta$-glucan synthase activity is stimulated by ATP or GTP. Similarly, Elorza et al. (1977) found that mannosyltransferase activity was inhibited by nucleoside diphosphates and suggested that rapid modulation of the rate of mannoprotein formation might be effected by changes in the nucleotide pool. We have recently reported a further mechanism involved in regulation of mannan synthesis in which mannosyltransferase activity is suppressed by a heat-labile, trypsin-sensitive inhibitor (Harrington \& Douglas, 1980). In the present study we have surveyed the effects of various nucleotides and sugar nucleotides on mannan synthesis in vitro and now report that mannosyltransferase activity is competitively inhibited by GDPglucose but enhanced by ATP. 


\section{METHODS}

Organisms and growth conditions. Saccharomyces cerevisiae X2180-1A (a) and its mutants defective in mannoprotein biosynthesis, LB1-3B mnn2-1a and LB1-10B mnn1-2a, were kindly supplied by Dr C. E. Ballou, University of California, Berkeley, U.S.A. They were grown aerobically, as described by Harrington \& Douglas (1980).

Preparation of spheroplast lysate and washed membrane fraction. These were prepared as described previously (Harrington \& Douglas, 1980) except that Zymolyase-5000 was used at a concentration of $0.7 \mathrm{mg} \mathrm{ml}^{-1}$ and incubation was for $60 \mathrm{~min}$ at $30^{\circ} \mathrm{C}$.

Mannosyltransferase assay. Mannosyltransferase activity was measured by following the incorporation of $\left[{ }^{14} \mathrm{C}\right.$ lmannose from GDP $\left[{ }^{14} \mathrm{C}\right]$ mannose into perchloric acid-precipitable material as described by Harrington \& Douglas (1980). The standard incubation mixture contained spheroplast lysate or washed membrane fraction at a protein concentration of $1 \mathrm{mg} \mathrm{ml} \mathrm{m}^{-1}$. The filtration procedure was modified slightly in that filters were prewashed with cold $1 \%(\mathrm{w} / \mathrm{v})$ mannose solution and precipitates on filters were washed with cold $0 \cdot 3 \mathrm{M}-\mathrm{HClO}_{4}$ $(20 \mathrm{ml})$ followed by more cold $1 \%$ mannose solution $(5 \mathrm{ml})$. This assay method measures the formation of both glycoproteins and glycolipids containing $\left[{ }^{14} \mathrm{C} \mid\right.$ mannose since these products co-precipitate on the filters.

$\beta$-Elimination of $\left[{ }^{14} \mathrm{C} \mid\right.$ mannoproteins. Following incubation, mannosyltransferase assay mixtures containing washed membrane fraction $\left(0.2 \mathrm{mg}\right.$ protein) were heated at $100^{\circ} \mathrm{C}$ for $3 \mathrm{~min}$, adjusted to $1 \mathrm{ml}$ with water and centrifuged $(1000 \mathrm{~g}, 5 \mathrm{~min})$. The pellets were washed twice with water, resuspended in $0.1 \mathrm{M}-\mathrm{NaOH}(1 \mathrm{ml})$ and incubated at room temperature $\left(18-20^{\circ} \mathrm{C}\right)$ for $18 \mathrm{~h}$. After neutralization with $2 \mathrm{M}$-acetic acid $(50 \mu \mathrm{l})$, the mixtures were centrifuged and the pellets washed twice with water. The pellets were finally transferred to scintillation vials with methanol $(1.5 \mathrm{ml})$. Methanol was removed by evaporation in vacuo and radioactivity was counted in toluene scintillant $(10 \mathrm{ml})$. Control mixtures were incubated for $18 \mathrm{~h}$ with water instead of alkali and zero-time controls were from assay mixtures containing heat-inactivated $\left(100^{\circ} \mathrm{C}\right.$ for 3 min) washed membrane fraction.

Radioactivity incorporated into lipids. Radioactive lipids were extracted from standard mannosyltransferase assay mixtures by two successive extractions with different chloroform/methanol mixtures. Assays were terminated by the addition of ice-cold chloroform $/$ methanol $(2: 1, \mathrm{v} / \mathrm{v} ; 2 \mathrm{ml})$ followed by thorough mixing. With zero-time controls, chloroform/methanol was added before GDP $\mid{ }^{14} \mathrm{C} /$ mannose. Each mixture was centrifuged at $2000 \mathrm{~g}$ for $10 \mathrm{~min}$ and the pellet was extracted twice with $2 \mathrm{ml}$ of the same solvent. $\mathrm{KCl}(0 \cdot 88 \%$, w/v: $1.5 \mathrm{ml}$ ) was added to the combined extracts $(6 \mathrm{ml})$ and the resultant lower phase was washed twice with theoretical upper phase $(1.5 \mathrm{ml})$ according to Folch et al. (1957). The washed lower phase was transferred to a scintillation vial, evaporated to dryness in vacuo and counted in toluene scintillant $(10 \mathrm{ml})$. The residual pellet was extracted twice with chloroform/methanol/water (10:10:3, by vol.; $2 \mathrm{ml})$ and the combined extracts were dried and counted. Individual lipids were separated by thin-layer chromatography of concentrated extracts $(50 \mu \mathrm{l})$ on plates of silica gel $\mathrm{G}$ (Merck) in chloroform/methanol/water $(65: 25: 4$, by vol.).

Degradation of sugar nucleotides. Degradation of ${ }^{14} \mathrm{C}$-labelled sugar nucleotides by enzyme preparations was assessed by separating the reaction products by paper chromatography. After incubation of mannosyltransferase assay mixtures, or mixtures containing equivalent concentrations of GDP| ${ }^{14} \mathrm{C} /$ glucose or UDP$\left[{ }^{14} \mathrm{C}\right.$ /glucose (Amersham) in place of GDP $\left[{ }^{14} \mathrm{C}\right.$ lmannose, reactions were terminated by heating at $100{ }^{\circ} \mathrm{C}$ for 3 min. The mixtures were applied as $2.5 \mathrm{~cm}$ bands to Whatman $3 \mathrm{MM}$ paper and subjected to descending chromatography. Following development, the radioactivity on each track was located by counting $1 \mathrm{~cm}$ segments in toluene scintillant $(5 \mathrm{ml})$. Radioactive components which neither remained at the origin nor co-migrated with sugar nucleotide standards were regarded as products of sugar nucleotide hydrolysis. Percentage degradation refers to the combined radioactivity in these products expressed as a percentage of the total radioactivity on the chromatogram.

Paper chromatography. This was carried out on Whatman $3 \mathrm{MM}$ paper with the descending solvent system isobutyric acid/1 $\mathrm{M}$ aqueous ammonia $(5: 3, \mathrm{v} / \mathrm{v})$. Unlabelled standard sugars were detected with alkaline silver nitrate (Trevelyan et al., 1950) and phosphate esters with perchloric acid/molybdate (Hanes \& Isherwood, 1949). Sugar nucleotides were visualized under ultraviolet light.

Protein determinations. Protein was estimated by the Lowry method using bovine plasma albumin as a standard. Before analysis, samples of spheroplast lysate and washed membrane fraction were digested in $0.5 \mathrm{M}-\mathrm{NaOH}$ at $100^{\circ} \mathrm{C}$ for $15 \mathrm{~min}$ in glass-stoppered tubes.

\section{RES.ULTS}

\section{Survey of effectors of mannosyltransferase activity}

Mannosyltransferase activity of both spheroplast lysate and washed membrane preparations was assayed in the presence of a variety of possible effectors, all at a final concentration 
Table 1. Effect of sugars and nucleotides on mannosyltransferase activity of $S$. cerevisiae

$\begin{gathered}\text { Addition to } \\ \text { incubation mixture } \\ \quad(1 \mathrm{mM})\end{gathered}$
None
Glucose
Mannose
$N$-Acetylglucosamine
Glucosamine
Cyclic AMP
AMP
ADP
ATP
GMP
GDP
GTP
UMP
UDP
UTP
P
PP

\begin{tabular}{|c|c|}
\hline \multicolumn{2}{|c|}{ Relative enzyme activity $(\%)^{*}$} \\
\hline $\begin{array}{c}\text { Spheroplast lysate } \\
\text { preparation }\end{array}$ & $\begin{array}{l}\text { Washed membrane } \\
\text { fraction }\end{array}$ \\
\hline $100 \cdot 0$ & $100 \cdot 0$ \\
\hline $101 \cdot 2 \pm 1 \cdot 8$ & $102 \cdot 5 \pm 1 \cdot 0$ \\
\hline $96 \cdot 3 \pm 5 \cdot 7$ & $89.4 \pm 3.4$ \\
\hline $97.2 \pm 1.0$ & $99.4 \pm 0.5$ \\
\hline $100 \cdot 4 \pm 6.0$ & $101 \cdot 8 \pm 3.6$ \\
\hline $98.6 \pm 3.9$ & $96.0 \pm 2.2$ \\
\hline $97.7 \pm 0.7$ & $97 \cdot 1 \pm 1 \cdot 4$ \\
\hline $119 \cdot 3 \pm 5 \cdot 3$ & $114 \cdot 1 \pm 2 \cdot 1$ \\
\hline $242.4 \pm 6 \cdot 3$ & $232.4 \pm 7.2$ \\
\hline $94 \cdot 9 \pm 3 \cdot 1$ & $100 \cdot 0 \pm 4 \cdot 4$ \\
\hline $38 \cdot 9 \pm 3 \cdot 2$ & $40.3 \pm 0.3$ \\
\hline $65 \cdot 0 \pm 3.4$ & $66.3 \pm 2.6$ \\
\hline $88.9 \pm 4.2$ & $105 \cdot 1 \pm 3 \cdot 3$ \\
\hline $101 \cdot 1 \pm 3 \cdot 8$ & $97 \cdot 1 \pm 1.4$ \\
\hline $73 \cdot 3 \pm 5 \cdot 5$ & $120.5 \pm 2.3$ \\
\hline $106.3 \pm 6.0$ & $120 \cdot 3 \pm 3.4$ \\
\hline $100 \cdot 0 \pm 5 \cdot 4$ & $120.9 \pm 5.4$ \\
\hline
\end{tabular}

* Activity is expressed as a percentage of that in standard incubation mixtures with no additions. Values quoted are means of at least three determinations, \pm the standard deviation.

Table 2. Effect of sugar nucleotides on mannosyltransferase activity of S. cerevisiae

$\quad \begin{gathered}\text { Addition to } \\ \text { incubation mixture } \\ \quad(1 \mathrm{~mm})\end{gathered}$
None
UDP- $N$-acetylglucosamine
ADPglucose
CDPglucose
dTDPglucose
UDPglucose
GDPglucose
UDPglucose + GDPglucose
UDPmannose
ADPmannose

$\begin{array}{cc}\begin{array}{c}\text { Spheroplast lysate } \\ \text { preparation }\end{array} & \begin{array}{c}\text { Washed membrane } \\ \text { fraction }\end{array} \\ 100.0 & 100.0 \\ 101.0 \pm 1.9 & 101.7 \pm 3.0 \\ 112.1 \pm 1.5 & 100.2 \pm 1.3 \\ 103.4 \pm 4 \cdot 8 & 91.5 \pm 1.6 \\ 99.5 \pm 3 \cdot 1 & 94.1 \pm 2.4 \\ 95.2 \pm 5.6 & 104.1 \pm 4.6 \\ 19.4 \pm 5.0 & 23.8 \pm 7.0 \\ 19.4 \pm 4.7 & 24.9 \pm 7.0 \\ 80.1 \pm 5.9 & 79.4 \pm 4.9 \\ 75.7 \pm 4.1 & 89.0 \pm 3.6\end{array}$

* Activity is expressed as a percentage of that in standard incubation mixtures with no additions. Values quoted are means of three determinations, \pm the standard deviation.

of $1 \mathrm{~mm}$ (Tables 1 and 2). The sugars and nucleoside monophosphates tested had little effect on enzyme activity (Table 1). ATP, however, stimulated activity in both preparations by more than $130 \%$. There was also slight stimulation by ADP while GTP and, more especially, GDP inhibited activity. UTP inhibited activity of the spheroplast lysate but stimulated that of the washed membrane fraction.

Only three of the eight sugar nucleotides tested affected mannosyltransferase activity by more than $12 \%$ (Table 2). ADPmannose and UDPmannose inhibited activity of both enzyme preparations by 11-24\%. GDPglucose, on the other hand, caused $81 \%$ and $76 \%$ inhibition with the spheroplast lysate and washed membrane preparations, respectively. When GDPglucose and UDPglucose were both included in reaction mixtures, inhibition was the same as that due to GDPglucose alone. Four sugar nucleotides were further tested over a range of concentrations up to $2 \mathrm{mM}$. GDPglucose was a potent inhibitor of mannosyltransferase activity, causing almost complete inhibition at $2 \mathrm{~mm}$. Inhibition by ADPmannose 
Table 3. Effect of ATP on mannosyltransferase activity of washed membrane fractions from wild-type and mutant strains of $S$. cerevisiae

$\begin{array}{lcc}\begin{array}{c}\text { Strain of } \\ S . \text { cerevisiae }\end{array} & \overbrace{\begin{array}{c}\text { Total mannan } \\ \text { synthesis }\end{array}}^{\begin{array}{c}\text { Relative enzyme activity (\%)* } \\ \text { with 5 mM-ATP }\end{array}} \begin{array}{c}\text { Non } \beta \text {-eliminable } \\ \text { synthesis }\end{array} \\ \text { X2180-1 A (wild-type) } & 172 & 791 \\ m n n 2 \text { mutant } & 179 & 213 \\ m n n 1 \text { mutant } & 142 & 132 \\ * \text { Activity is expressed as a percentage of that without ATP. }\end{array}$

and UDPmannose was maximal at about $1 \mathrm{mM}$ while UDP- $N$-acetylglucosamine had little effect on enzyme activity at any of the concentrations tested.

\section{Stimulation of mannosyltransferase activity by ATP}

The formation of dolichyl monophosphate mannose from GDPmannose by liver microsomes is inhibited by rapid hydrolysis of the substrate by nucleotide pyrophosphatase but substrate degradation can be prevented by ATP (Vessey \& Zakim, 1975). In the present study, stimulation of mannosyltransferase activity by ATP was not due to the protection of GDP $\left[{ }^{14} \mathrm{C}\right]$ mannose from pyrophosphatase degradation. Paper chromatography of standard reaction mixtures containing $100 \mu \mathrm{g}$ of spheroplast lysate protein revealed that less than $1 \%$ of the substrate was hydrolysed to mannose 1-phosphate or mannose during incubation.

The short oligosaccharides attached to serine or threonine residues in yeast mannoproteins are released by $\beta$-elimination on treatment with mild alkali (Sentandreu \& Northcote, 1968). This technique was used to analyse the nature of mannan synthesized in vitro. ATP enhanced synthesis of the non $\beta$-eliminable portion of mannan much more than synthesis of total mannan with enzyme preparations from the wild-type (Table 3 ). These results may indicate a preferential stimulation of polysaccharide chain synthesis. With enzyme preparations from two mutant strains unable to form complete polysaccharide chains (Ballou, 1976), ATP enhanced synthesis of total mannan and non $\beta$-eliminable mannan almost equally.

The extent to which mannan synthesis was stimulated by ATP varied with different enzyme preparations. Furthermore, ATP-mediated activation tended to diminish following storage of enzyme preparations at $-20^{\circ} \mathrm{C}$, although it could sometimes be restored at higher ATP concentrations. Since it is known that some mannosyltransferase activities are lost more rapidly than others during storage at low temperatures (Sharma et al., 1974; Parodi, 1979) these observations may also imply selective stimulation of some transferases by ATP.

\section{Inhibition of mannosyltransferase activity by GDPglucose}

Mannosyltransferase activity of the spheroplast lysate preparation was measured at different substrate concentrations. A Lineweaver-Burk plot of the results (Fig. 1) revealed biphasic kinetics with two $K_{\mathrm{m}}$ values $(0.13 \mathrm{~mm}$ and $0.53 \mathrm{~mm})$ and two $V$ values $[6.94$ and $11.43 \mathrm{nmol} \mathrm{h}^{-1}$ (mg protein)-1] for low and high substrate concentrations, respectively. Similar biphasic kinetics have been described recently by Guttierrez \& Ruiz-Herrera (1979) for mannosyltransferase activity in membrane fractions from Mucor rouxii. In the presence of $1 \mathrm{mM}$-GDPglucose the $V$ values remained unaltered while the apparent $K_{\mathrm{m}}$ values increased to $0.23 \mathrm{~mm}$ and $0.63 \mathrm{~mm}$. These results indicate that GDPglucose is a competitive inhibitor of mannosyltransferases. This conclusion is supported by the data in Fig. 2 which show that inhibition of mannan synthesis by GDPglucose becomes obvious only at GDPglucose :GDPmannose ratios of $2: 1$, or greater. 


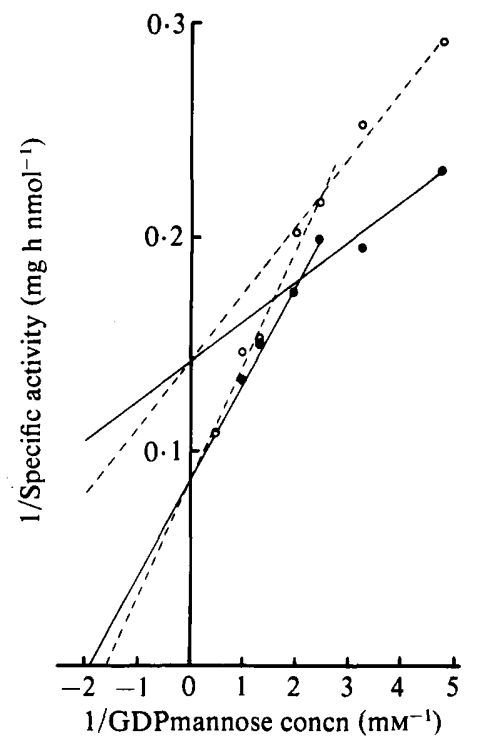

Fig. 1. Lineweaver-Burk plot of specific mannosyltransferase activity of a spheroplast lysate preparation against GDPmannose concentration with (O) or without (O) $1 \mathrm{mm-GDPglucose.} \mathrm{Mannosyl-}$ transferase activity was measured in the standard assay with GDP $\mid{ }^{14} \mathrm{C} /$ mannose $(578 \mathrm{pmol}: 100 \mathrm{nCi}$ ) and carrier GDPmannose $(0 \cdot 2-2 \cdot 0 \mathrm{~mm})$.

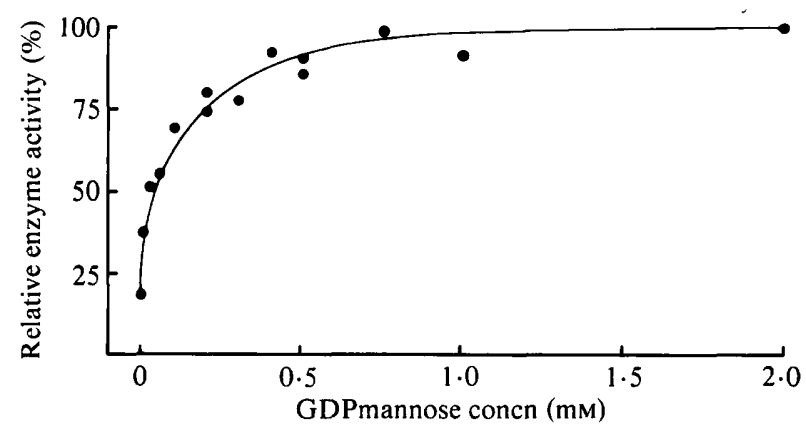

Fig. 2. Inhibition of mannosyltransferase activity of a spheroplast lysate preparation by GDPglucose at different concentrations of GDPmannose. Mannosyltransferase activity was measured in the standard assay with $1 \mathrm{~mm}$-GDPglucose, GDP $\left[{ }^{14} \mathrm{C} /\right.$ mannose $(578 \mathrm{pmol} ; 100 \mathrm{nCi})$ and carrier GDPmannose $(0.0-2.0 \mathrm{~mm})$. Activity is expressed as a percentage of that in the standard incubation mixture without GDPglucose.

GDPglucose inhibited the formation of mannose-containing lipids. When spheroplast lysate $\left(0.1 \mathrm{mg}\right.$ protein) was incubated with GDP $\left[{ }^{14} \mathrm{C} /\right.$ mannose under standard conditions and then extracted with two chloroform/methanol mixtures (chloroform/methanol, $2: 1, \mathrm{v} / \mathrm{v}$; followed by chloroform/methanol/water, 10:10:3, by vol.) radioactive label equivalent to 27 pmol $\left[{ }^{14} \mathrm{C}\right]$ mannose $\mathrm{h}^{-1}$ (mg protein) ${ }^{-1}$ was found in the combined extracts. The lipids were not fully characterized but, from their solubilities in organic solvents and $R_{F}$ values on thin-layer chromatography, appeared to comprise a mixture of dolichyl monophosphate mannose (Tanner, 1969; Sentandreu \& Lampen, 1971) and dolichyl diphosphate-bound oligosaccharides (Lehle \& Tanner, 1975, 1978). When $1 \mathrm{mM}$-GDPglucose was included in incubation mixtures there was no detectable radioactive label in chloroform/methanol extracts i.e. less than $3 \mathrm{pmol} \mathrm{h}^{-1}(\mathrm{mg} \text { protein })^{-1}$. 


\section{GDPglucose glucohydrolase activity}

If $\mathrm{GDP}\left[{ }^{14} \mathrm{C}\right.$ /mannose was replaced in assay mixtures by an equivalent concentration $(116 \mathrm{pmol} ; 20 \mathrm{nCi})$ of GDP $\left[{ }^{14} \mathrm{C}\right.$ glucose, no radioactivity was found in lipid extracts. This suggested that although GDPglucose inhibits the formation of mannolipids, it does not do so by competing with GDPmannose for the available dolichyl phosphate. Moreover, no detectable radioactive label was incorporated from GDP $\left[{ }^{14} \mathrm{C}\right.$ lglucose into perchloric acidprecipitable material under these conditions. However, when the products of reaction mixtures containing spheroplast lysate and GDP $\left[{ }^{14} \mathrm{C}\right.$ lglucose were separated by paper chromatography it was found that the sugar nucleotide had been largely degraded to $\left[{ }^{14} \mathrm{C}\right]$ glucose. This was probably due to the action of GDPglucose glucohydrolase, a soluble enzyme, first reported in $S$. cerevisiae by Sonnino et al. (1966), which catalyses the hydrolysis of GDPglucose to GDP and glucose. Degradation was rapid and specific. Only $1 \%$ of GDP $\left[{ }^{14} \mathrm{C}\right.$ lmannose $(116 \mathrm{pmol} ; 20 \mathrm{nCi})$ was hydrolysed during incubation with spheroplast lysate protein $\left(2 \mathrm{mg} \mathrm{ml}^{-1}\right)$ for $20 \mathrm{~min}$ at $30^{\circ} \mathrm{C}$. Similar incubation of GDP $\left[{ }^{14} \mathrm{C}\right]-$ glucose and UDP $\left[{ }^{14} \mathrm{C}\right.$ lglucose $(116 \mathrm{pmol} ; 20 \mathrm{nCi})$ with spheroplast lysate $\left(4 \mathrm{mg} \mathrm{ml}^{-1}\right)$ resulted in $85.7 \%$ and $9.5 \%$ degradation, respectively.

Although carrier-free GDP $\left[{ }^{14} \mathrm{C}\right.$ lglucose was rapidly hydrolysed by spheroplast lysate preparations, less than $1 \%$ of the sugar nucleotide was converted to glucose at the concentration (1 mM) used to test its action on mannosyltransferase activity. Thus, the inhibitory effect of GDPglucose on mannan synthesis is not simply due to the production of GDP by the glucohydrolase. This conclusion is supported by the data in Tables 1 and 2 which show that GDPglucose inhibits mannan synthesis by $80 \%$ whereas GDP causes only $60 \%$ inhibition and glucose has no effect.

The extent of GDP $\left[{ }^{14} \mathrm{C}\right.$ lglucose degradation in standard assay mixtures was greater with spheroplast lysate (up to $93 \%$ degradation) than with washed membrane fraction $(57 \%)$. Degradation was reduced to $17.4 \%$ by washing the membrane fraction a further four times in $50 \mathrm{~mm}$-Tris/ $\mathrm{HCl}$ buffer $(\mathrm{pH} \mathrm{7.2)}$. This more extensive washing also promoted the incorporation of radioactivity from $\mathrm{GDP} \mid{ }^{14} \mathrm{Clglucose}$ into perchloric acid-precipitable material to $35 \cdot 7 \mathrm{pmol} \mathrm{h}^{-1}$ (mg protein $)^{-1}$.

\section{DISCUSSION}

Of the various nucleotides tested, GDP, GTP and ATP had the greatest effect on mannosyltransferase activity (Table 1). Inhibition by GDP is to be expected since it is a product of the transferase reaction. Furthermore, GDP, and GTP in the presence of phosphatases, are known to reverse the formation of dolichyl monophosphate mannose by liver preparations (Richards \& Hemming, 1972) and by membrane fractions from S. cerevisiae (Tanner et al., 1971).

The mechanism by which ATP stimulates mannosyltransferase activity is less clear. The results in Table 3 suggest a preferential effect on the synthesis of mannoprotein polysaccharide chains. Related observations have been made in studies on glycoprotein synthesis by mammalian systems. For example, various nucleotides, including ATP, have been found to diminish the synthesis of dolichyl monophosphate mannose while simultaneously enhancing the formation of lipid-bound oligosaccharides by retina or rat-liver preparations (Kean, 1977; Richard et al., 1978). Recently, ATP and GTP have been shown to stimulate yeast $1,3-\beta$-glucan synthase which appears to be located on the inner surface of the plasma membrane (Shematek et al., 1980; Shematek \& Cabib, 1980). The characteristics of activation by the two nucleotides differed in that activation by ATP was time- and temperaturedependent and required the presence of a heat-stable, dialysable supernatant factor. On the basis of their results, Shematek \& Cabib (1980) have proposed a model for nucleotidemediated regulation of glucan synthase activity. 
While UDPglucose is known to be a precursor for $1,3-\beta$-linked glucan in yeast (Sentandreu et al., 1975; López-Romero \& Ruiz-Herrera, 1977; Shematek et al., 1980) the role of GDPglucose in glucan synthesis is not fully established. Bálint et al. (1976) have reported the incorporation of low levels of $\left[{ }^{14} \mathrm{C}\right]$ glucose from GDP $\left[{ }^{14} \mathrm{C}\right]$ glucose into a product which they tentatively characterized as a $1,6-\beta$-glucan containing some $1,3-\beta$-linkages in the sidechains. Thus, GDPglucose may function as a precursor for the minor 1,6- $\beta$-glucan component of the yeast wall. Further evidence might be obtained from studies with enzyme preparations devoid of GDPglucose glucohydrolase activity. In the present investigation, extensive washing of membrane fractions decreased this activity but did not remove it entirely. If, indeed, GDPglucose is a precursor for glucan synthesis, our finding that it is also a competitive inhibitor of mannan synthesis would suggest that the two synthetic systems are strictly segregated in vivo. Moreover, the presence of a hydrolase with strict specificity for GDPglucose implies the existence of complex regulatory mechanisms.

This work was supported by a Science Research Council studentship awarded to C. R. H.

\section{REFERENCES}

Bálint, S., FARKaš, V. \& Bauer, S. (1976). Biosynthesis of $\beta$-glucans catalysed by a particulate enzyme preparation from yeast. FEBS Letters 64 , 44-47.

Ballou, C. E. (1976). Structure and biosynthesis of the mannan component of the yeast cell envelope. Advances in Microbial Physiology 14, 93-158.

Behrens, N. H. \& CABIB, E. (1968). The biosynthesis of mannan in Saccharomyces carlsbergensis. Journal of Biological Chemistry 243, 502-509.

Elorza, M. V., Larriba, G., Villanueva, J. R. \& SENTANDREU, R. (1977). Biosynthesis of the yeast cell wall: selective assays and regulation of some mannosyl transferase activities. Antonie van Leeuwenhoek 43, 129-142.

FleEt, G. H. \& ManNERs, D. J. (1976). Isolation and composition of an alkali-soluble glucan from the cell walls of Saccharomyces cerevisiae. Journal of General Microbiology 94, 180-192.

Folch, J., LeEs, M. \& Sloane-Stanley, G. H. (1957). A simple method for the isolation and purification of total lipids from animal tissues. Journal of Biological Chemistry 226, 497-509.

Guttierrez, F. \& RuIz-HERrERA, J. (1979). Mannosyl transferase from yeast and hyphal forms of Mucor rouxii. Experimental Mycology 3, 351-362.

Hanes, C. S. \& Isherwood, F. A. (1949). Separation of the phosphoric esters on the filter paper chromatogram. Nature, London 164, 1107-1112.

Harrington, C. R. \& Douglas, L. J. (1980). Inhibition and activation of mannan synthesis in Saccharomyces cerevisiae spheroplast lysates. Journal of Bacteriology 142, 852-858.

JUNG, P. \& TANNER, W. (1973). Identification of the lipid intermediate in yeast mannan biosynthesis. European Journal of Biochemistry 37, 1-6.

KEAN, E. L. (1977). The biosynthesis of mannolipids and mannose-containing complex glycans by the retina. Journal of Supramolecular Structure 7 , 381-395.

Lehle, L. \& TANNER, W. (1975). Formation of lipid-bound oligosaccharides in yeast. Biochimica et biophysica acta 399, 364-374.
Lehle, L. \& TANNER, W. (1978). Biosynthesis and characterization of large dolichyl diphosphate-linked oligosaccharides in Saccharomyces cerevisiae. Biochimica et biophysica acta 539, 218-229.

López-Romero, E. \& RuIz-Herrera, J. (1977). Biosynthesis of $\beta$-glucans by cell-free extracts from Saccharomyces cerevisiae. Biochimica et biophysica acta 500, 372-384.

Manners, D. J., Masson, A. J. \& Patterson, J. C. $(1973 a)$. The structure of a $\beta-(1 \rightarrow 3)$-D-glucan from yeast cell walls. Biochemical Journal 135, 19-30.

Manners, D. J., Masson, A. J., Patterson, J. C., BJÖRNDAL, H. \& LiNDBERG, B. $(1973 b)$. The structure of a $\beta-(1 \rightarrow 6)$-D-glucan from yeast cell walls. Biochemical Journal 135, 31-36.

NAKAJima, T. \& Ballou, C. E. (1975). Yeast mannoprotein biosynthesis: solubilization and selective assay of four mannosyltransferases. Proceedings of the National Academy of Sciences of the United States of America 72, 3912-3916.

PARodi, A. J. (1979). Biosynthesis of yeast mannoproteins. Synthesis of mannan outer chain and of dolichol derivatives. Journal of Biological Chemistry 254, 8343-8352.

RichaRd, M., Tytgat, F. \& Louisot, P. (1978). Study of nuclear mannosyltransferase: lipid intermediates. Biochimie 60, 593-599.

Richards, J. B. \& Hemming, F. W. (1972). The transfer of mannose from guanosine diphosphate mannose to dolichol phosphate and protein by pig liver endoplasmic reticulum. Biochemical Journal 130, 77-93.

Sentandreu, R. \& Lampen, J. O.•(1971). Participation of a lipid intermediate in the biosynthesis of Saccharomyces cerevisiae LK2G12 mannan. FEBS Letters 14, 109-113.

Sentandreu, R. \& Northcote, D. H. (1968). The structure of a glycopeptide isolated from the yeast cell wall. Biochemical Journal 109, 419-432.

Sentandreu, R., Elorza, M. V. \& Villanueva, J. R. (1975). Synthesis of yeast wall glucan. Journal of General Microbiology 90, 13-20.

Sharma, C. B., Babczinski, P., Lehle, L. \& TANNER, W. (1974). The role of dolicholmono- 
phosphate in glycoprotein biosynthesis in Saccharomyces cerevisiae. European Journal of Biochemistry 46, 35-41.

ShemateK, E. M. \& CABIB, E. (1980). Biosynthesis of the yeast cell wall. II. Regulation of $\beta-(1 \rightarrow 3)$ glucan synthetase by ATP and GTP. Journal of Biological Chemistry 255, 895-902.

Shematek, E. M., BraAtZ, J. A. \& Cabib, E. (1980), Biosynthesis of the yeast cell wall. I. Preparation and properties of $\beta-(1 \rightarrow 3)$ glucan synthetase. Journal of Biological Chemistry 255, 888-894.

Sonnino, S., Carminatti, H. \& CABIB, E. (1966). Guanosine diphosphate D-glucose glucohydrolase. Archives of Biochemistry and Biophysics 116, 26-33.
AND L. J. DOUGLAS

TANNER, W. (1969). A lipid intermediate in mannan biosynthesis in yeast. Biochemical and Biophysical Research Communications 35, 144-150.

TANNer, W., Jung, P. \& Behrens, N. H. (1971). Dolicholmonophosphates: mannosyl acceptors in a particulate in vitro system of Saccharomyces cerevisiae. FEBS Letters 16, 245-248.

Trevelyan, W. E., Procter, D. P. \& Harrison, J. S. (1950). Detection of sugars on paper chromatograms. Nature, London 166, 444-445.

VESSEY, D. A. \& ZAKIM, D. (1975). Characterization of the reaction of GDP-mannose with dolichol phosphate in liver membranes. European Journal of Biochemistry 53, 499-504. 